\title{
Physician engagement: a necessary but reciprocal process
}

\section{A. Donald Milliken MB}

Competing interests: None declared.

This article has been peer reviewed.

Correspondence to: Donald Milliken, dmilliken@live.ca

CMAJ 2014. DOI:10.1503 /cmaj.131178
$\mathrm{P}$ hysicians drive a high proportion of costs in health care. Without their engagement, managing costs is difficult. There is often tension between administrative groups who are hired to manage health care costs effectively and physicians who wish to provide effective treatment. Sometimes, patient care suffers as a result of poor engagement.

Greater "physician engagement" has been touted as a fix for a variety of ills in the delivery of health care today. Taitz and colleagues ${ }^{1}$ stated that physician engagement could be described as "physicians owning the most optimal way in which health care is delivered so that it is focused, smooth, effective and achieves desired patient outcomes" or as "physicians working to reduce unjustifiable variation in care." Clark, ${ }^{2}$ however, emphasized a more cooperative approach, in which doctors act within their normal roles to maintain and enhance the performance of the organization "which itself recognizes this commitment in supporting and encouraging high-quality care." Yet "physician engagement" can sometimes seem like code for "managing physicians," which creates polarity. Unless physicians and health care administrative bodies both engage equally in a respectful and sophisticated way, such polarity will continue, and poor cooperation and suboptimal communication will result in reduced quality of care for patients.

Despite substantial changes over the last half century in the way health care is delivered, the primary function of any health care organization remains to provide a competent practitioner - a physician, nurse or other clinician - at the bedside in a patient's hour of need. Although care has evolved to become more complex and medical teams may be larger today, success of the health care organization must still be judged by

\section{KEY POINTS}

- The fundamental purpose of a health care organization is to support the willing, competent and engaged clinician's interaction with each patient.

- Engaged physicians are essential for high-functioning health care organizations, but the process of engagement must be supported by an organizational culture of openness.

- The engagement process has to be reciprocal, with the organization recognizing and supporting the clinician's needs, and vice versa. its ability to properly support this function.

Physician partnership and engagement is essential to an organization wishing to deliver safe, high-quality health care. ${ }^{3}$ In business, "engagement" defines a mutual relation in which the business values the employee and the employee values the business, ${ }^{4}$ recognizing that every worker in an organization may choose to do the minimum required or to exceed it. In health care, the traditional focus has been on how to achieve the organization's quality agenda by trying to engage physicians. However, the Institute for Healthcare Improvement suggests that we reframe the approach by asking how the hospital can engage in the physicians' quality agenda, thereby acknowledging that physicians are interested in quality, particularly in terms of patient outcomes and personal waste (such as wasted time). ${ }^{5}$

Many health care professionals would describe themselves as "battered," "pressured," "hassled" and "misunderstood" by the people who shape their working environment. ${ }^{6}$ However, policymakers and health executives feel no less pressured $^{6}$ than physicians. Thus, to achieve excellence in patient care, this polarity must be dissolved.

In Canada and some other countries with publicly funded health care systems, nonclinical administrators are accountable to the politicians and officials in ministries of health who drive their employment, pay and promotion. International examples show that, when boards and administrative jobs can change with the next election (or sooner), attention is focused on short-term results and job security. ${ }^{7}$ In health care, many decisions carry the potential for both positive and negative outcomes, both of which should be examined. However, a system that wants only good news risks sweeping its problems under the carpet until the consequences can no longer be ignored.

For example, in at least two Canadian provinces (Ontario and British Columbia), hospitals or health authorities have made unilateral attempts to rewrite medical staff bylaws, reducing physician autonomy and muzzling dissent. ${ }^{8}$ The provincial medical associations objected, noting the absence of meaningful consultation with the affected physicians and the negative effects on physician advocacy for patients. ${ }^{8}$ Others have

All editorial matter in CMAJ represents the opinions of the authors and not necessarily those of the Canadian Medical Association. 
suggested that all physicians should become salaried, ${ }^{910}$ which, in the Canadian context, would yield the same result. These concerns were reiterated when the Canadian Broadcasting Corporation identified that employees under management control, such as nurses, would not speak out about what happened within their organizations for fear of workplace discipline or dismissal. ${ }^{11}$

Literature from both the United States and the United Kingdom details how to achieve high performance in clinical organizations; bylaw changes or muzzling are not included. One careful and representative review, focusing on what organizations do, rather than what they say they do, described the key characteristics of high-performing organizations. ${ }^{12}$

Within high-functioning organizations, leaders agree that patient care is the primary function among the competing interests of care, teaching and research. Such organizations have a continuing drive to improve; simply being "good enough" is not acceptable. This ethos contrasts with that of less-effective organizations that are more often satisfied with where they are, focusing on comparisons to peer groups and referencing external awards or accreditations as proof of a good job.

In addition, strong organizations develop a firm alliance between senior front-line clinicians and executives, who regularly visit the clinical front line. Systems of accountability for quality, safety and service blend central and decentralized responsibility. In accepting that the tactics for improvement have to occur at the unit level, senior executives actively support and monitor activities rather than rely on summary reports with little follow-up in underperforming areas.

To improve outcomes and reduce error, good organizations place high importance on measurements that support work redesign, rather than just those needed for external reporting. Such information is kept up-to-date and widely shared within and outside of the organization.

Finally, relationships between administrators, physicians, nurses and other professional staff are collaborative in good organizations, and not based on positional authority. Decision-making devolves to those with the greatest expertise or situational knowledge and is not based on rank or position.

Many more recent reports have echoed these themes, emphasizing that collaborative engagement between clinical and administrative staff is the necessary prerequisite for an organization to consistently deliver and improve high-quality care.,13
To understand whether the primary function of the health care system is well supported, we must ask whether the system supports the competent clinician, as well as whether the competent clinician supports the system. Positive answers to both questions are required for true bilateral engagement.

Physician engagement is only part of the solution; administrative engagement is equally important, or disillusionment and disengagement ensues. For Canadian health care to engage physicians more effectively, changes in the culture of nonphysician administration are required. Our system needs to encourage and support more clinicians' involvement in effectively directing and guiding the activities of the organization.

\section{References}

1. Taitz JM, Lee TH, Sequist TD. A framework for engaging physicians in quality and safety. BMJ Qual Saf 2012;21:722-8.

2. Clark J. Medical engagement: too important to be left to chance. London (UK): The King's Fund; 2012. Available: www.kingsfund .org.uk/sites/files/kf/medical-engagement-nhs-john-clark-leadership -review2012-paper.pdf (accessed 2012 Dec. 18).

3. Leadership and engagement for improvement in the NHS: together we can. Report from The King's Fund leadership review 2012. London (UK): The King's Fund; 2012. Available: www.kingsfund .org.uk/publications/leadership-engagement-for-improvement-nhs. (accessed 2012 Dec. 18)

4. MacLeod D, Clarke N. Engaging for success: enhancing performance through employee engagement. London (UK): Department of Business, Innovation and Skills; 2009. Available: www.bis.gov.uk/files/file52215.pdf. (accessed 2013 May 1).

5. Reinertsen JL, Gosfield AG, Rupp W, et al. Engaging physicians in a shared quality agenda. Cambridge (MA): Institute for Healthcare Improvement; 2007. Available: www.ihi.org/knowledge/Pages /IHIWhitePapers/EngagingPhysiciansWhitePaper.aspx (accessed 2013 Dec. 2).

6. Berwick DM. Foreward. In: Quality by design: a clinical microsystems approach. Nelson EC, Batalden PB, Godfrey MM, editors. San Francisco (CA): Jossey-Bass; 2007: xix-xxi.

7. Francis R. The Mid Staffordshire NHS Foundation Trust Public Inquiry: executive summary of the final report. London (UK): The Stationary Office; 2013. Available: www.midstaffspublic inquiry.com (accessed 2013 Apr. 15).

8. Vogel L. Ontario Hospital Association proposes to scuttle privileges model for doctors. CMAJ 2010;182:E441-2.

9. Vogel L. Doctors' groups a roadblock to reform, researchers say. CMAJ 2010;182:E440

10. Lewis S. Want improved healthcare performance? Treat Canadian doctors like Finnish teachers. Toronto (ON): Longwoods Publishing Corporation; 2013. Available: www.longwoods.com /content/23212 (accessed 2013 Mar. 15).

11. The Fifth Estate: rate your hospital. Canadian Broadcasting Corporation [Toronto] 2013 Apr 12.

12. Keroack MA, Youngberg BJ, Cerese JL, et al. Organizational factors associated with high performance in quality and safety in academic medical centers. Acad Med 2007;82:1178-86.

13. Atkinson A, Spurgeon P, Clark J, et al. Engaging doctors: what can we learn from trusts with high levels of medical engagement? Coventry (UK): NHS Institute for Innovation and Improvement and Academy of Medical Royal Colleges; 2011. Available: www.aomrc .org.uk/projects/enhancing-engagement-in-medical-leadership.html (accessed 2012 Dec. 18).

Affiliation: Department of Psychiatry, Island Health, Victoria, BC 